\title{
Luminescence of $\mathrm{SiO}_{2}$ Film Implanted with Ge Negative Ions
}

\author{
Nobutoshi Arai*, Hiroshi Tsuji, Masatomi Harada*, Masashi Hattori, Tuyoshi \\ Satoh*, Masayuki Ohsaki, Hiroshi Kotaki*, Toyotsugu Ishibashi, Yasuhito Gotoh \\ and Junzo Ishikawa \\ Department of Electronic Science and Engineering, Kyoto University, Nishikyo-ku, Kyoto 606-8501, Japan \\ Fax: 81-75-383-2284, e-mail: tsuji@kuee.kyoto-u.ac.jp \\ *Advanced Technology Research Laboratories, SHARP Corporation, Tenri 632-8567, Japan \\ Fax: 81-743-65-2393, e-mail: arai@ulab.tnr.sharp.co.jp
}

\begin{abstract}
The cathodeluminescencs (CL), photoluminescence (PL), and electroluminescence (EL) properties of $\mathrm{Ge}$ implanted $\mathrm{SiO}_{2}$ films $\left(\mathrm{SiO}_{2}: \mathrm{Ge}\right)$ were investigated. The $\mathrm{SiO}_{2}$ films on $\mathrm{Si}$ substrate were implanted with $\mathrm{Ge}$-negative ions. The implanted $\mathrm{Ge}$ atom concentrations in the films were 3 and 6 at. \%. Ge nanoparticles were formed in the $\mathrm{SiO}_{2}$ films after annealing. CL, $\mathrm{PL}$ and EL were observed at wavelengths around $400 \mathrm{~nm}$ from the $\mathrm{SiO}_{2}$ : Ge films. $\mathrm{CL}$ of $\mathrm{GeO}_{2}$ films were also investigated. The $\mathrm{CL}$ intensity from the $\mathrm{GeO}_{2}$ films is obviously lower than that from the $\mathrm{SiO}_{2}: \mathrm{Ge}$ films with 6 at.\% of Ge atomic concentration. Strong EL from large area of the films was not only to be easily seen with naked eye but also to be measured its wavelength. Ooperating voltage was an order of magnitude lower and the emitting area was two orders of larger than those reported previously. These results suggested that annealing of $\mathrm{SiO}_{2}: \mathrm{Ge}$ films in moderate oxidative atmosphere is suitable method for the strong luminescence due to Ge-related oxygen deficient center (Ge-ODC).
\end{abstract}

Key words: Nanoparticles, Ion implantation, Oxide film, Germanium Negative ion, Luminescence

\section{INTRODUCTION}

A Semiconductor is attractive materials for light-emitting devices. Especially semiconductor materials compatible with the standard Si technology are desired for the development of light emission source for communication in a LSI chip. For example, silicon and germanium in silicon-dioxide layers are expected to apply to electroluminescence source in LSI chips, since 500-nm-thick $\mathrm{SiO}_{2}$ films implanted with $\mathrm{Ge}^{+}$ions were reported to show blue and violet electroluminescence by applying a voltage of $350 \mathrm{~V}$ [1]. However, it is not only required to decrease the operation voltage [2] but also required to increase the luminescence intensity for various application. In order to meet this requirement, we have tried to implant $\mathrm{Ge}$ ions into a shallow region in $\mathrm{SiO}_{2}$ layer on $\mathrm{Si}$ substrate by using a negative-ion implantation method with multi-energy. Moreover, we studied the cathodeluminescence (CL) of thermally grown $\mathrm{GeO}_{2}$ films and of $\mathrm{Ge}$ implanted $\mathrm{SiO}_{2}$ films $\left(\mathrm{SiO}_{2}: \mathrm{Ge}\right)$. Negative-ion implantation has an advantage of almost "charge-up free" feature for insulators [3]. Therefore, the penetration depth of ions can be controlled correctly with a relatively low energy implantation into a thin insulator such as silicon dioxide. Moreover, the technique is suitable for careful examination about implanted atoms in thin dielectric films such as $\mathrm{SiO}_{2}$ films, because the charge up can make accidental dispersion of implanted atoms and can cause break down of dielectric films to make accidental defects in the films.

\section{EXPERIMENTAL}

Germanium negative ions $\left(\mathrm{Ge}^{-}\right)$were implanted at room temperature into $\mathrm{SiO}_{2}$ films with thickness of 100 and $50 \mathrm{~nm}$ thermally grown on Silicon substrate (Shin-Etsu Chemical Co., Ltd.). We used a multi-energy implantation technique to make a regions of the $\mathrm{SiO}_{2}: \mathrm{Ge}$ films. In the multi-energy implantation, the $\mathrm{Ge}^{-}$were implanted three times into the same sample by changing the energies of 50, 20 and $10 \mathrm{keV}$. Maximum $\mathrm{Ge}$ atom concentrations in the $\mathrm{SiO}_{2}$ :Ge films were ranging from 3 or 6 at.\%. For example, the concentration profiles for $\mathrm{Ge}$ atoms about 3 at.\% at peak concentration is shown in Fig. 1. The profiles were calculated by using the Transport of Ions in Matter (TRIM-DYN) program [4].

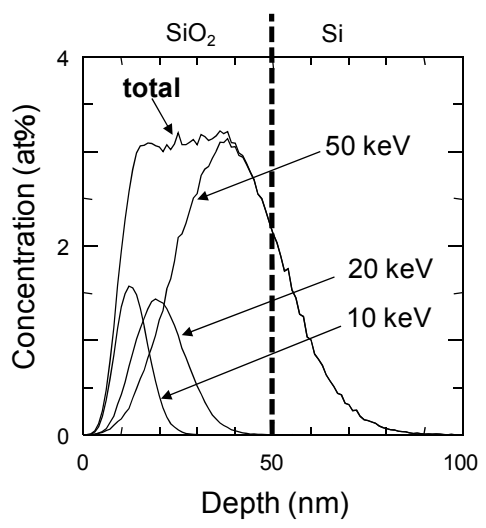

Fig. 1. Depth profile of $\mathrm{Ge}$ atoms implanted into $\mathrm{SiO}_{2}$ medium calculated by using TRIM-DYN program under conditions of multi-energy implanted at $50 \mathrm{keV}$ with $7.0 \times 10^{15}$, $20 \mathrm{keV}$ with $1.6 \times 10^{15}$ and $10 \mathrm{keV}$ with $1.1 \times 10^{15} \mathrm{ions} / \mathrm{cm}^{2}$. 


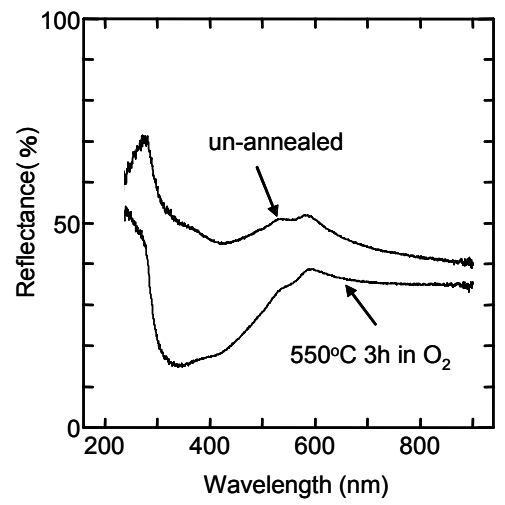

Fig. 2. Optical reflectanc spectra for Germanium substrate before and after thermal annealing in $\mathrm{O}_{2}$ atmosphere.

The total concentration curve in Fig. 1 expects the formation of a layer with Ge concentration of about 3 at.\% from $10 \mathrm{~nm}$ to $40 \mathrm{~nm}$ in depth. The gas pressure during the implantation was kept less than $1 \times 10^{-4} \mathrm{~Pa}$. We expected to obtain $\mathrm{SiO}_{2}$ : Ge films with about 30-nm-thick Ge implanted region by the multi-energy implantation. The $\mathrm{Ge}$ implanted $\mathrm{SiO}_{2}: \mathrm{Ge}$ films were then annealed at $800{ }^{\circ} \mathrm{C}$ for $1 \mathrm{~h}$ by an electrical oven in a quartz tube with a $\mathrm{N}_{2}$ gas flow $(50 \mathrm{ml} / \mathrm{min})$ under low vacuum condition by a rotary pump $(400 \mathrm{l} / \mathrm{min})$.

The $\mathrm{GeO}_{2}$ films were grown by oxidation of $\mathrm{Ge}$ substrates (Furuuchi chemical Co., Ltd., Japan) at $550^{\circ} \mathrm{C}$ for $3 \mathrm{~h}$ in $\mathrm{O}_{2}$ gas flow. $\mathrm{A} \mathrm{GeO}_{2}$ films with thickness of about $100 \mathrm{~nm}$ were formed on the Ge substrates. Fig. 2 shows reflectance spectra obtained from the Ge substrate before and after thermal oxidization. The reflectance is obviously decreased after thermal oxidization. The reduction of reflectance indicates that germanium atoms near the surface were oxidized.

CL of the $\mathrm{SiO}_{2}: \mathrm{Ge}$ and $\mathrm{GeO}_{2}: \mathrm{Ge}$ films were investigated with using an electron beam at $5 \mathrm{keV}$.

$\mathrm{PL}$ and EL of the $\mathrm{SiO}_{2}$ :Ge films were investigated in RF-5300PC Shimadzu spectrometer with a R955 Hamamatsu photomultiplier. For PL observation, 150W Xenon lamp within the spectrometer was used as a

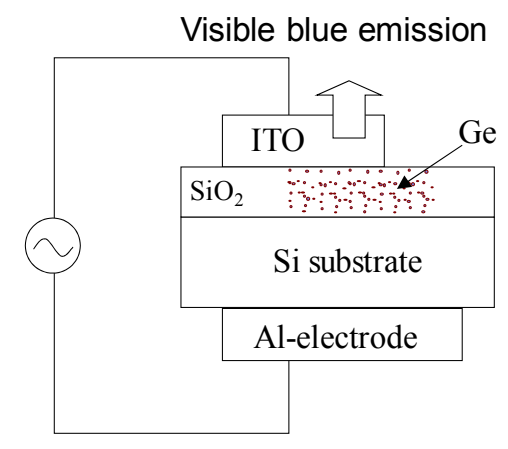

Fig. 3. A schematic view of light emitting devices with simple MOS structer.

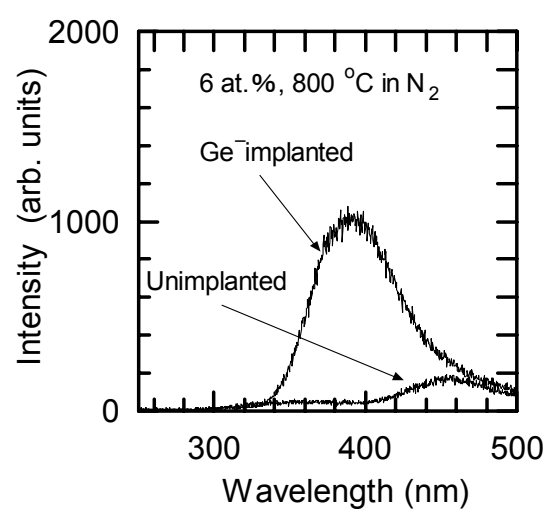

Fig. 4. CL spectra of $\mathrm{Ge}$ implanted $\mathrm{SiO}_{2}: \mathrm{Ge}$ film in comparison to unimplanted $\mathrm{SiO}_{2}$ film.

source of $240 \mathrm{~nm}$ excitation light. For EL observation, metal-oxide-semiconductor (MOS) device structures as shown in Fig. 3. were prepared by sputtering indium tin oxide (ITO) as front side electrode and evaporating Al as rear side electrode.

Cross-sectional TEM images were obtained using a scanning-type TEM of EM-002B (Topcon Techno), operating at $200 \mathrm{keV}$.

\section{RESULTS AND DISCUSSION}

Cathodeluminescence (CL) of the $\mathrm{SiO}_{2}$ :Ge films with 6 at.\% implanted Ge peak concentration after annealing at $800^{\circ} \mathrm{C}$ in $\mathrm{N}_{2}$ for $1 \mathrm{~h}$ were investigated. Fig. 4 shows $\mathrm{CL}$ spectra of the Ge implanted $\mathrm{SiO}_{2}$ :Ge film and from an unimplanted $\mathrm{SiO}_{2}$ film at room temperature measurement. The unimplanted $\mathrm{SiO}_{2}$ film showed only broad luminescence peak at around $460 \mathrm{~nm}$, but the Ge implanted $\mathrm{SiO}_{2}$ :Ge film showed large sharp luminescence peak at around $400 \mathrm{~nm}$. This luminescence peak is well agreed with the CL spectra reported by Rebohle et al [1] and H. J. Fitting et al [5]. Therefore, the peak around $400 \mathrm{~nm}$ is considered to be due to oxygen deficient center (ODC) attributing to two fold-coordinate $\mathrm{Ge}$ atoms.

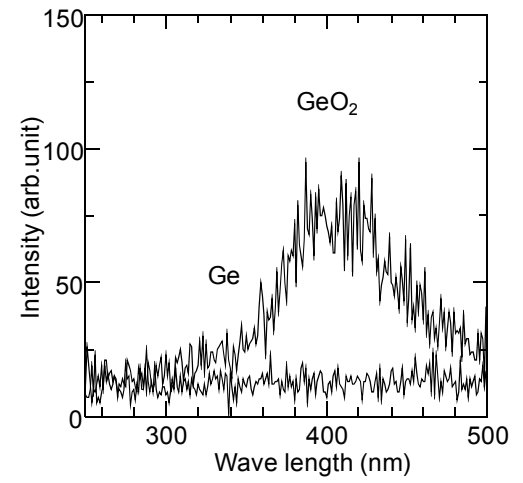

Fig. 5. CL spectra of thermally grown $\mathrm{GeO}_{2}$ film in comparison to Ge substrate before thermal annealing. 


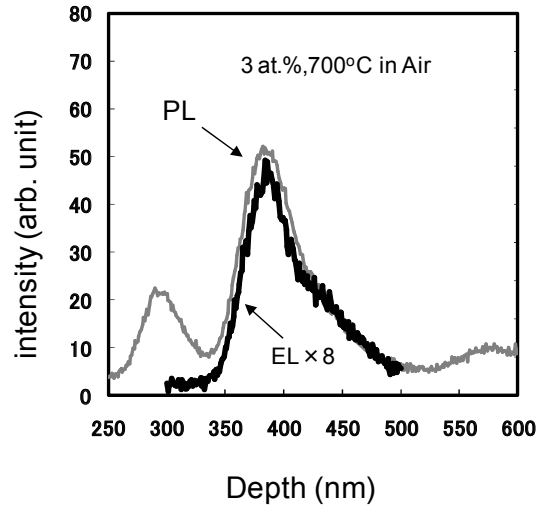

Fig. 6. PL and EL spectra of $\mathrm{SiO}_{2}$ :Ge films with 3 at.\% implanted Ge peak concentration after annealing at $700^{\circ} \mathrm{C}$ in Air for $2 \mathrm{~h}$

Fig. 5 shows CL spectra of the thermally grown $\mathrm{GeO}_{2}$ films on Ge substrate and from the Ge substrate before oxidation at room temperature measurement. The Ge substrate before oxidation could scarcely show luminescence between 250 and $500 \mathrm{~nm}$, but the $\mathrm{GeO}_{2}$ film showed weak luminescence peak at around $400 \mathrm{~nm}$. These luminescence peaks seem corresponding to above CL peak in Fig. 4. Although total amounts of mono-oxidized $\mathrm{Ge}$ atoms and di-oxidized $\mathrm{Ge}$ atoms in the thermally grown $\mathrm{GeO}_{2}$ films were much more than those in the Ge implanted $\mathrm{SiO}_{2}$ : Ge films, the intensity of luminescence from the $\mathrm{GeO}_{2}$ films was obviously not more than that from the $\mathrm{Ge}$ implanted $\mathrm{SiO}_{2}$ : Ge films. CL intensity from the $\mathrm{GeO}_{2}: \mathrm{Ge}$ films was a order of magnitude lower than that from $\mathrm{SiO}_{2}$ : Ge films with only 6 at.\% of $\mathrm{Ge}$ atom concentration after annealing.

These results suggested that the strong luminescence could be generated by tuning condition of $\mathrm{Ge}$ implantation and subsequence annealing.

$\mathrm{PL}$ and $\mathrm{EL}$ of the $\mathrm{SiO}_{2}: \mathrm{Ge}$ films with 3 at.\% implanted Ge peak concentration after annealing at $700^{\circ} \mathrm{C}$ in low pressure air for $2 \mathrm{~h}$ were investigated at room temperature. For EL measurement the ITO electrode of about $10 \mathrm{~mm}$ square was much larger than that of about $1 \mathrm{~mm}$ in diameter in previous work by other groups [1], and was enough large for Ge implanted area of $8 \mathrm{~mm}$ in diameter. Strongly emitted luminescence was expected due to forming much $\mathrm{GeO}$ by moderate oxidation of $\mathrm{Ge}$. At applying $1 \mathrm{kHz}-\mathrm{AC}$ voltage of about $35 \mathrm{~V}$, strong EL from large area were not only to be easily seen with naked eye but also to be measured its wavelength by RF-5300PC Shimadzu spectrometer. Fig. 6 shows EL and PL spectra of the Ge implanted $\mathrm{SiO}_{2}$ :Ge film at 3 at. $\%$ after annealing at $700^{\circ} \mathrm{C}$ at room temperature measurement. The Ge implanted $\mathrm{SiO}_{2}: \mathrm{Ge}$ film showed large luminescence peak at around $400 \mathrm{~nm}$ for EL as well as PL. This EL spectra measured in wavelength of 350 to $500 \mathrm{~nm}$ is well agreed with the PL spectra. Luminescence peak at around $300 \mathrm{~nm}$ was shown in PL but not in EL. This disappearance in EL may be due to ITO which is opaque for light in shorter wavelength than around $300 \mathrm{~nm}$. These luminescence spectra were well agreed with spectra reported by Rebohle et al [1], and

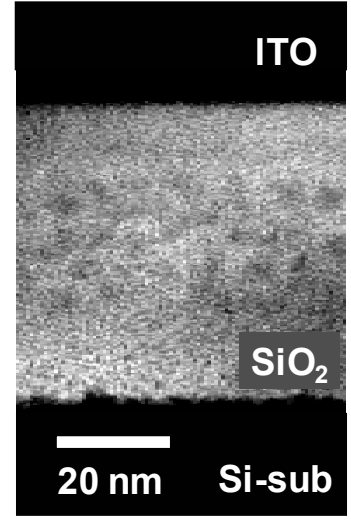

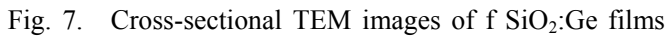
with 3 at.\% implanted $\mathrm{Ge}$ peak concentration after annealing at $700^{\circ} \mathrm{C}$ in Air for $2 \mathrm{~h}$.

moreover, the operating voltage was an order of magnitude lower and the emitting area was two orders of larger than those reported by them.

These improvements would be realized by relatively long time annealing at suitable temperature for $\mathrm{Ge}$ nanoparticle-formation as well as in suitable oxidative atmosphere for $\mathrm{GeO}$-formation.

The TEM images of the films are shown in Fig. 7. Ge nanoparticles with 2-3 $\mathrm{nm}$ in diameter were formed in the middle of the film at $11-37 \mathrm{~nm}$ in depth.

The Ge nanoparticles were formed with gathering $\mathrm{Ge}$ atoms implanted in the films. Some surplus Ge atoms in the films could form leak passes like ion irradiated defects and could not contribute light emission. The suitable annealing reduced the surplus $\mathrm{Ge}$ atoms and irradiated defects in the films so that the films were of greater stability than those in the previous reports [1]. In the previous report, the $\mathrm{Ge}$ implanted $\mathrm{SiO}_{2}: \mathrm{Ge}$ films were annealed at relatively high temperature around $1000^{\circ} \mathrm{C}$ for relatively short time in a inert gas.

These results suggested that the strong luminescence was generated due to oxidation of $\mathrm{Ge}$ nanoparticles in the $\mathrm{SiO}_{2}: \mathrm{Ge}$ films. It might indicate that not only Ge-oxidation but also Ge nanoparticles-formation was important for strong light emission source with Ge-ODC. Nanoparticles might be suitable for generation and/or stabilization of the ODC.

\section{CONCLUSION}

Flat profiles of $\mathrm{Ge}$ atom concentration in some regions of $\mathrm{SiO}_{2}$ films can be formed by using a multi-energy implantation technique. In the multi-energy implantation, $\mathrm{Ge}^{-}$ions were implanted three times into the same $\mathrm{SiO}_{2}$ films by changing the energies of 50,20 and $10 \mathrm{keV}$. The CL spectra of the Ge implanted $\mathrm{SiO}_{2}: \mathrm{Ge}$ films showed peaks around $400 \mathrm{~nm}$ in wavelength. We also studied the thermally grown $\mathrm{GeO}_{2}$ films. Although it showed luminescence peak corresponding to the same position peak from the Ge implanted $\mathrm{SiO}_{2}$ : Ge films, the intensity of luminescence from the thermally grown $\mathrm{GeO}_{2}$ films was obviously weaker than that from the $\mathrm{Ge}$ implanted $\mathrm{SiO}_{2}: \mathrm{Ge}$ films. The $\mathrm{SiO}_{2}: \mathrm{Ge}$ films with 3 at.\% implanted $\mathrm{Ge}$ peak concentration after annealing at $700^{\circ} \mathrm{C}$ in low pressure air for $2 \mathrm{~h}$ showed large 
luminescence peak at around $400 \mathrm{~nm}$ for EL as well as PL. The operating voltage was lower and the emitting area was larger than those ever reported. This improvement might be realized by the annealing in moderate oxidative atmosphere. These results might provide guidance in strong light emission in UV-blue region from $\mathrm{SiO}_{2}$ :Ge films.

\section{REFERENCES}

[1] L. Rebohle, J. Von Borany, R.A. Yankov, W. Skorupa, I.E. Tyschenko, H. Froeb, and K. Leo, Appl. Phys. Lett. 71 [19] (1997) 2809-2811.

[2] J.M.J. Lopes, F.C. Zawislak, M. Behar, P.F.P. Fichtner, L. Rebohle, and W. Skarupa, J. Appl. Phys. 94 [9] (2003) 6059-6064.

[3] J. Ishikawa, H. Tsuji, Y. Toyota, Y. Gotoh, K. Matsuda, M. Tanho, and S. Sakai, Nucl. Instr. Methods, B96 (1995) 7-12.

[4] J.P. Biersack, Nucl. Instr. Meth. B 27 (1987) 21.

[5] H. -J. Fitting, T. Barfels, A.N. Trukhin, B. Schmidt, A. Gulans, A. von Czarnowski, J. Non-Crystalline Solids, 303 (2002) 218-231.

(Received January 10, 2009; Accepted February 15, 2010) 